\title{
From Laboratory Breakthrough to Technological Realization: The Development Path for Solid Acid Fuel Cells
}

\author{
by Calum R.I. Chisholm, Dane A. Boysen, Alex B. Papandrew, Strahinja Zecevic, SukYal Cha, \\ Kenji A. Sasaki, Áron Varga, Konstantinos P. Giapis, and Sossina M. Haile
}

pen up any textbook on fuel cells and the reader finds a list of five classic types of fuel cells, each differentiated by the nature of the electrolyte: polymer electrolyte membrane (or sometimes proton exchange membrane), phosphoric acid, alkali, molten carbonate, and solid oxide. This article deals with a newcomer on the scene of fuel cell science and technology-the superprotonic solidacid fuel cell ${ }^{1,2}$ - that expands this list from five to six. Like its cousins, the solid-acid fuel cell, or SAFC, offers tremendous environmental benefits in the generation of electricity (and mechanical work) from chemical fuels. $^{3}$ These include zero regulated emissions, high efficiency leading to reduced carbon dioxide emissions, suitability to hydrogen, and low noise and mechanical vibrations. Unlike other fuel cells, however, SAFCs operate at warm temperatures using a truly solid electrolyte. The occurrence of liquid-like proton transport in a noncorrosive, solid material implies unique opportunities for new approaches to fuel cell design, construction, and operation.

\section{Which Solid Acid?}

The solid acids of interest for fuel cell application are those whose chemistry is based on oxyanion groups $\left(\mathrm{SO}_{4}{ }^{2-}\right.$, $\mathrm{PO}_{4}{ }^{3-}, \mathrm{SeO}_{4}{ }^{2-}, \mathrm{AsO}_{4}{ }^{3-}$ ), in turn, linked together by hydrogen bonds and charge balanced by large cation species $\left(\mathrm{Cs}^{+}\right.$, $\left.\mathrm{Rb}^{+}, \mathrm{NH}_{4}{ }^{+}, \mathrm{K}^{+}\right)$. A select few among these compounds undergo a polymorphic, structural transition from an ordered state (with oxyanion groups in fixed orientation) to a highly disordered one, in which the oxyanion groups undergo almost free reorientation. Despite the high degree of disorder, the materials display sharp crystalline diffraction patterns as a consequence of the fixed position for the heavy metal cations and the fixed center of mass of the oxyanion groups. Accompanying this order-disorder transition is a dramatic increase in proton conductivity, by as much as 4 orders of magnitude in the case of $\mathrm{CsHSO}_{4}$. Above the transition, the conductivity is typically $\sim 10^{-2} \mathrm{~S} / \mathrm{cm}$, approaching the value of the best aqueous systems, and the activation energy for proton transport is $\sim 0.35$ eV. ${ }^{1}$ This combination of features has led to the term superprotonic to describe the nature of both the high conductivity phase and the transition itself. As an aside, we note that despite the overwhelming evidence to the contrary, there are those who continue to hold that the rise in conductivity at the superprotonic transition is due merely to a transient dehydration phenomenon rather than a true polymorphic transformation. ${ }^{4}$ This unfortunate position has had no bearing on the progress of SAFC development.

Superprotonic behavior has been confirmed under atmospheric pressures in the solid acid compounds $\mathrm{CsHSO}_{4}, 5$ $\mathrm{CsHSeO}_{4},{ }^{5} \quad \mathrm{CsH}_{2} \mathrm{PO}_{4},{ }^{6} \quad \mathrm{Cs}_{3} \mathrm{H}\left(\mathrm{SeO}_{4}\right)_{2},{ }^{7}$ $\mathrm{Rb}_{3} \mathrm{H}\left(\mathrm{SeO}_{4}\right)_{2},{ }^{7} \quad\left(\mathrm{NH}_{4}\right)_{3} \mathrm{H}\left(\mathrm{SO}_{4}\right)_{2},{ }^{8}$ among others, and several mixed cesium sulfate-phosphates. ${ }^{9}$ The transition temperature ranges from as low as $91^{\circ} \mathrm{C}$ in $\mathrm{Cs}_{2}\left(\mathrm{HSO}_{4}\right)\left(\mathrm{H}_{2} \mathrm{PO}_{4}\right)^{10}$ to as high as $228^{\circ} \mathrm{C}$ in $\mathrm{CsH}_{2} \mathrm{PO}_{4}{ }^{4,6}$ The conductivity in the superprotonic phase is sufficiently high for each of these materials to warrant consideration for fuel cell implementation. However, criteria beyond simply conductivity must be considered. An examination of the list of superprotonic compounds indicates that almost every single one is based on oxyanions of column 16 elements: S and Se. Careful studies of acid sulfates and selenates have revealed that these compounds undergo a detrimental reaction with hydrogen as would be present in the fuel cell anode ${ }^{11}$

$$
\begin{aligned}
& 2 \mathrm{MHXO}_{4}+4 \mathrm{H}_{2} \rightarrow \\
& \mathrm{M}_{2} \mathrm{XO}_{4}+\mathrm{H}_{2} \mathrm{X}+4 \mathrm{H}_{2} \mathrm{O} \\
& 2 \mathrm{M}_{3} \mathrm{H}\left(\mathrm{XO}_{4}\right)_{2}+7 \mathrm{H}_{2} \rightarrow \\
& 3 \mathrm{M}_{2} \mathrm{XO}_{4}+4 \mathrm{H}_{2} \mathrm{X}+4 \mathrm{H}_{2} \mathrm{O}
\end{aligned}
$$

where $M=C s, R b$, etc. and $X=S$, Se. Furthermore, the reduction reaction is catalyzed by typical anode electrocatalysts (Pt, etc.) and even the mixed sulfate-phosphate compounds are not immune. Worse, the byproduct of the reaction product, $\mathrm{H}_{2} \mathrm{~S}$ or $\mathrm{H}_{2} \mathrm{Se}$, is an extreme poison to the fuel cell anode catalyst and, as a consequence, even a modest extent of reaction severely degrades the fuel cell power output. With this appreciation of the transport properties and thermodynamics of solid acids, only one candidate amongst known compounds remains a viable fuel cell electrolyte: $\mathrm{CsH}_{2} \mathrm{PO}_{4}$.

\section{Understanding $\mathrm{CsH}_{2} \mathrm{PO}_{4}$}

But $\mathrm{CsH}_{2} \mathrm{PO}_{4}$ is not without its own challenges. A key disadvantage of this phosphate is the relatively high superprotonic transition temperature, $228^{\circ} \mathrm{C}$ under ambient pressures. All compounds in which protons are incorporated are subject to thermodynamic driving forces favoring dehydration at high temperature. Specifically, the reaction

$$
\mathrm{CsH}_{2} \mathrm{PO}_{4} \rightarrow \mathrm{CsPO}_{3}+\mathrm{H}_{2} \mathrm{O}
$$

is increasingly favored as the temperature is increased to achieve the superprotonic state. Fortunately, chemical thermodynamics can also be called upon to rescue the situation. Under application of a suitable water partial pressure, Reaction 3 can be driven toward the left and the dehydration reaction suppressed. A complete study of the temperature and water partial pressure dependence of the dehydration behavior has provided a road map for identifying safe conditions for fuel cell operation (Fig. 1a). ${ }^{12,13}$

A second challenge in working with $\mathrm{CsH}_{2} \mathrm{PO}_{4}$ is the high plasticity or ductility that emerges in the superprotonic state. In the case of $\mathrm{CsHSO}_{4}$, it has been shown that perfect single crystals can be literally twisted into the shape of breakfast pastries without fracture. ${ }^{14}$ In a fuel cell, application of pressure to isolate the anode and cathode chambers implies that ductile behavior is highly undesirable and indeed the electrolyte can be completely expelled and an electrical short circuit encountered. However, a remarkably simple solution exists to this plasticity problem. By introducing $10 \mathrm{wt} \% \mathrm{SiO}_{2}$ (15 vol\%, 2 $\mu \mathrm{m}$ average particle size) and forming a composite electrolyte, the steady state strain rate is lowered from 8.1 to $1.7 \mathrm{~cm} / \mathrm{cm} \cdot \min$ (Fig. 1b). ${ }^{14}$ The impact on conductivity is minimal, lowering by it by just $20 \%$ in the superprotonic phase.

\section{Fuel Cell Operation}

With these challenges understood, one can then begin to design fuel cells that take advantage of the benefits inherent in moderate temperature operation in conjunction with a truly solid electrolyte. Using mechanically mixed, composite electrodes of $\mathrm{Pt}+\mathrm{CsH}_{2} \mathrm{PO}_{4}$, pre-commercial SAFCs 
Chisholm, et al.

(continued from previous page)

routinely draw peak power densities of $180 \mathrm{~mW} / \mathrm{cm}^{2}$ when operated on hydrogen / air at $250^{\circ} \mathrm{C}$ under ambient pressures; they display degradation rates of tens of microvolts per hour in constant current operation over periods of several hundred hours. Furthermore, these values of power output and stability of single membrane-electrode assemblies (MEAs) are almost directly replicated in 20-cell stacks (Fig. 2). Standard MEAs at Superprotonic, Inc. are 2 inches in diameter $\left(15 \mathrm{~cm}^{2}\right.$ active area) with electrolyte thicknesses of 50 $\mu \mathrm{m}$ and Pt loadings of $4 \mathrm{mg} / \mathrm{cm}^{2}$, and these MEAs serve as the basis for stacks with net $50 \mathrm{~W}$ power output. Larger cells up to 5 inches $\left(105 \mathrm{~cm}^{2}\right.$ active area), with similar physical characteristics, have also been successfully fabricated. In all cases, comparison of the fuel cell polarization curves with the electrolyte area specific resistance $\left(0.2 \Omega \mathrm{cm}^{2}\right.$ at 50 $\mu \mathrm{m}, 250^{\circ} \mathrm{C}$ ) indicates that the bulk of the voltage losses are due to the electrodes, and of these, the cathode is the limiting component. ${ }^{4,16}$ Furthermore, degradation is largely limited to the chemical and microstructural evolution of the cathode. Before turning toward efforts to improve durability and enhance cathode electrocatalysis rates, it is valuable to consider some additional milestones that have been reached with SAFCs.

The temperatures at which SAFCs are operated, $\sim 250^{\circ} \mathrm{C}$, suggest both a high degree of fuel stream impurity tolerance and suitability to operation on fuels more complex than hydrogen. Indeed, tolerance to CO levels as high as $20 \%$ has been demonstrated even in the absence of $\mathrm{Ru}$ as an alloying agent for the Pt anode catalyst (Fig. 3a), as has tolerance to $\mathrm{H}_{2} \mathrm{~S}, \mathrm{NH}_{3}, \mathrm{CH}_{3} \mathrm{OH}$, $\mathrm{C}_{3} \mathrm{H}_{8}$, and $\mathrm{CH}_{4}$ to levels of 100 ppm, 100 ppm, $5 \%, 3 \%$, and $5 \%$, respectively. For operation on reformed hydrocarbons, this characteristic greatly simplifies the reforming system by largely eliminating the need for gas clean-up. In the case of methanol, it is possible to simplify the system even further by incorporating reforming catalysts, which, like the SAFC, operate optimally at $\sim 250^{\circ} \mathrm{C},{ }^{17}$ directly into the fuel cell anode. The integration is particularly attractive because the heat released during fuel cell operation can be absorbed by the endothermic reforming reaction, ${ }^{18}$ overcoming the tremendous challenge of heat removal encountered in conventional, large-scale fuel cell systems. We have operated SAFCs with suitably modified anodes, using the base metal reforming catalyst, $\mathrm{Cu} / \mathrm{Zn} /$ $\mathrm{Al}_{2} \mathrm{O}_{3}, 17$ on vaporized methanol-water mixtures and measured power densities that are within $90-95 \%$ of those obtained from equivalent hydrogennitrogen mixtures, for current densities
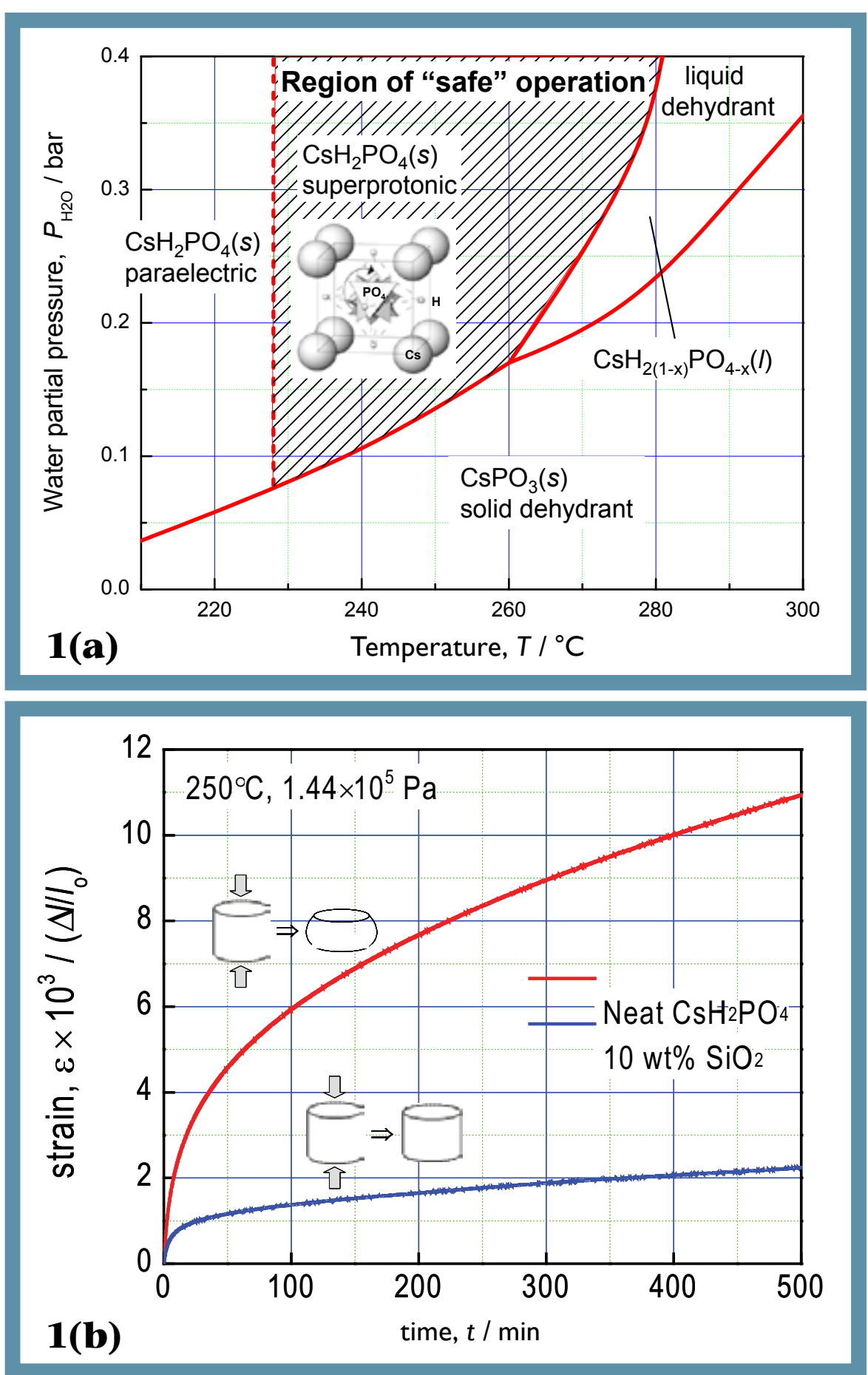

Fig. 1. Operational considerations for solid acid fuel cells based on $\mathrm{CsH}_{2} \mathrm{PO}_{4}$. (a) Phase stability diagram, and (b) mechanical deformation behavior under constant stress.

as large as $0.5 \mathrm{~A} / \mathrm{cm}^{2}$ (Fig. 3b). Thus, the expectations of fuel stream flexibility due to moderate temperature operation are indeed fulfilled in SAFCs.

\section{Challenges and Opportunities for SAFCS}

Despite the impressive improvement in performance of SAFCs from their inception a decade ago, significant additional progress must be made before they can enter a broad range of commercial applications. The key barriers are summarized as durability and cost, both of which are connected to the characteristics of the cathode.

For most applications requiring kilowatts of power, fuel cell operation for thousands of hours (auxiliary, backup, remote) to tens of thousands of hours (distributive and automotive) is necessary, where power output must remain at typically $80 \%$ of rated power. By this metric, state-of-the-art SAFCs have lifetimes only on the order of 1000-2000 h. In terms of costs, the acceptable entry price point for fuel cell systems to achieve mass adoption 


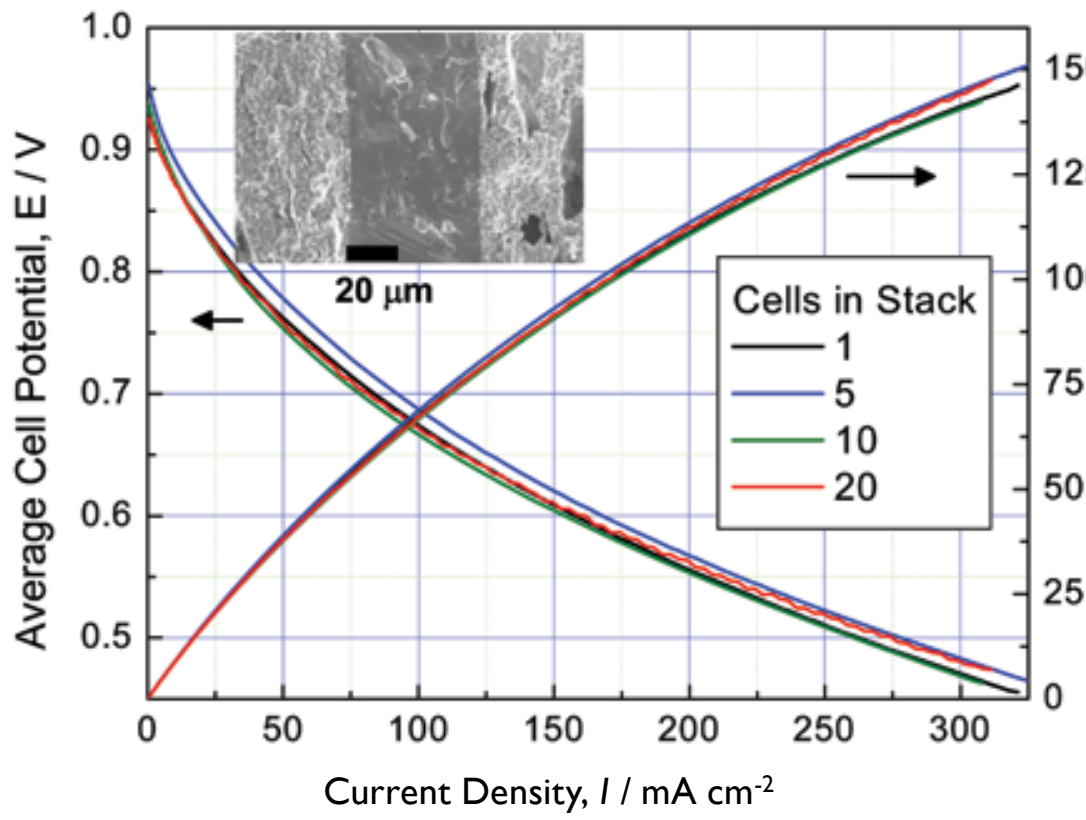

150 "ह

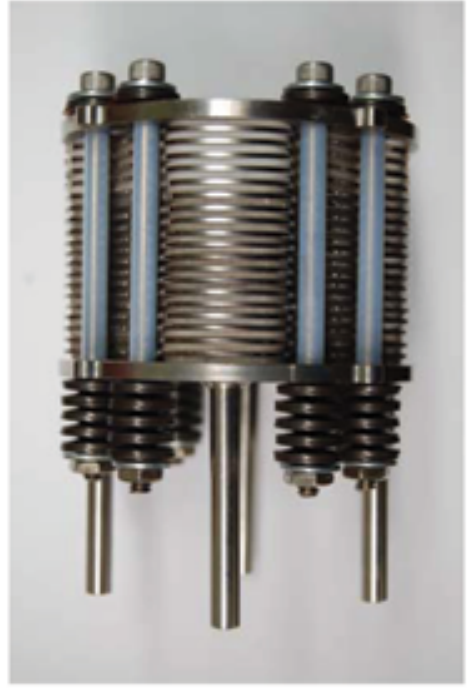

Fig. 2. (Left) Fuel cell polarization and power density curves for SAFC stacks manufactured at Superprotonic with inset showing scanning electron microscope image of a typical MEA; and (right) a 50W net stack constructed from such MEAs. Morphologically, solid acid fuel cells are similar to solid oxide fuel cells, with a dense 50 um electrolyte supported on a porous anode. Here, however, the components of the thin, porous cathode are identical to those of the anode. The planar power densities are retained on increasing the number of cells in the stack indicating negligible electrical resistance in the interconnect metals.

in early commercial markets is often quoted at $\sim \$ 1000 / \mathrm{kW} .{ }^{19}$ Even with the stack advantages (metal parts, polymer seals) and system level simplification attainable using SAFCs (ease in reforming, gas clean-up, cooling, and hydration/water management), today's system costs are estimated to exceed this target number for system price by a factor of $2-3$. What follows is a discussion of the source of these challenges and the efforts underway to address them.

We have several indications that SAFC degradation is almost entirely due to changes at the cathode. Key among these is the observation that, when operated as a hydrogen pump at 0.5 $\mathrm{A} / \mathrm{cm}^{2}$, a standard SAFC cell displays negligible changes in cell voltage for periods up to $500 \mathrm{~h}$. Microstructural examination of SAFC electrodes operated in conventional fuel cell mode reveals that the anode retains the as-prepared, high-porosity microstructure, whereas regions of the cathode appear densified and penetrated by the previously distinct electrolyte layer. Our interpretation is that the high overpotential at the cathode generates heat, accelerating the rate of creep of the electrolyte into the electrode and inducing densification. In turn, this decreases triple point density (the contact points between the electrolyte, the catalyst, and the phase), limits gas diffusion pathways, and, in severe instances, also deteriorates electrical connectivity. Our initial attempts to enhance microstructural stability through the introduction of additional components

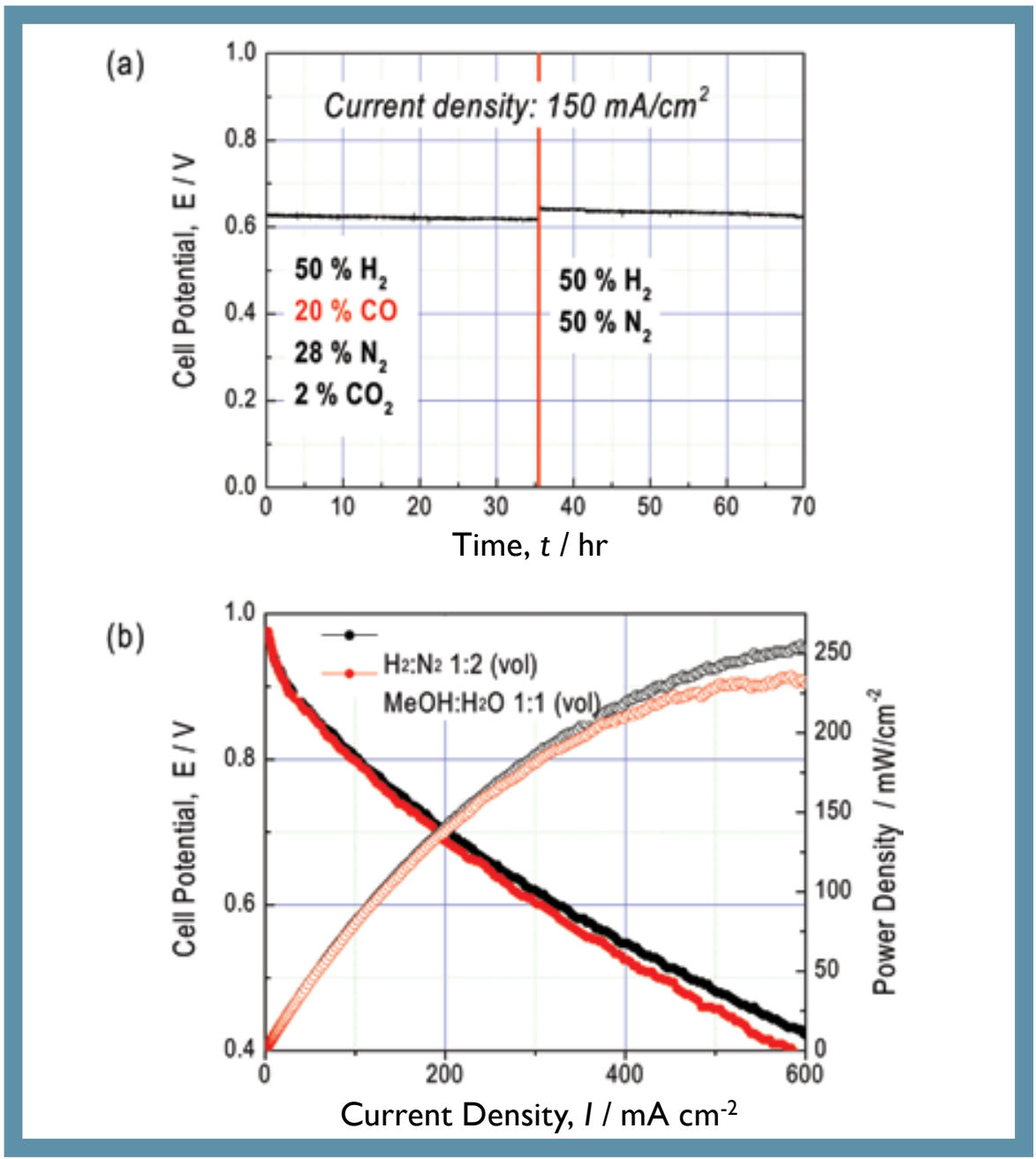

Fig. 3. Solid-acid fuel cell operation on (a) reformate with 20\% CO; and (b) methanol supplied as vapor in a 1:1 molar ratio with $\mathrm{H}_{2} \mathrm{O}$. 
Chisholm, et al.

(continued from previous page)

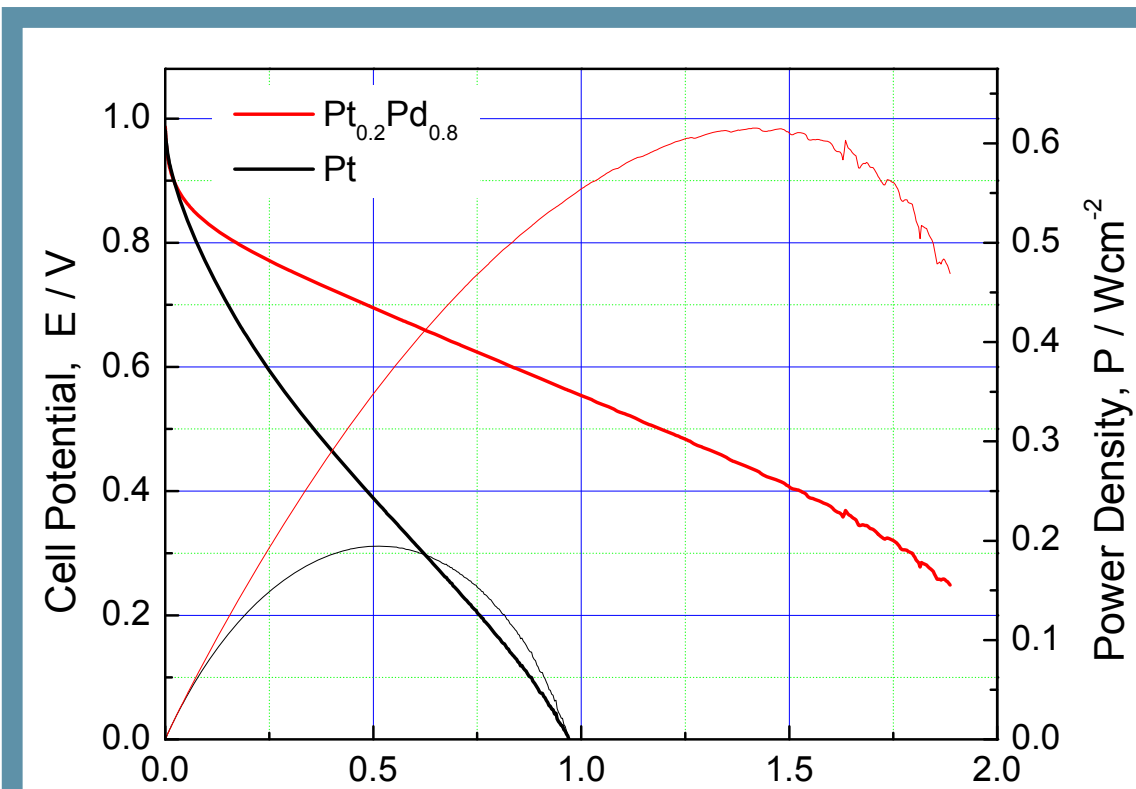

Current Density, $I / \mathrm{mA} \mathrm{cm}^{-2}$

Fig. 4. Comparison of polarization and power density curves for SAFCs operated on Pt and on $P t_{0.2} P d_{0.8}$ cathode catalysts. Anode catalyst is Pt in both cases.

to the composite cathode have, in some cases, improved SAFC lifetimes, but have generally been accompanied by decreases in performance. Specifically, while hydrophilic materials like silica can impede the creep of the electrolyte by binding to it, such materials typically also decrease the protonic conductivity in the electrode. On the other hand, hydrophobic materials such as carbon and Teflon can repel the advance of the electrolyte, but these tend to decrease the electrolyte-catalyst interaction and therefore the triple phase boundary density. An alternative approach is then to enhance the catalytic activity of the cathode so as to lower the overpotential and, ideally, obtain durability comparable to that observed for the anode.

With respect to cost, the key metric is not the absolute cost of any fuel cell system, but, as is widely appreciated, the cost per unit power output. Decreasing the cost/power ratio can be achieved either by decreasing the materials costs (per unit area of MEA) or increasing the fuel cell power density, or both. At present, the precious metals loading in the SAFC stack are cost-prohibitive (22 $\mathrm{mg} \mathrm{Pt} / \mathrm{W})$, and attaining higher power densities with materials less costly than Pt can ideally address both the numerator and denominator in the cost/ power ratio. By exploring alternatives to $\mathrm{Pt}$ in combination with a reduction to the thickness of the electrolyte layer (from 50 to $25 \mu \mathrm{m}$ ), we have recently achieved SAFC power densities of over $0.5 \mathrm{~W} / \mathrm{cm}^{2}$ at operational voltages $(0.6$
V) and with total platinum group metal (PGM) loadings of less than $4 \mathrm{mg} / \mathrm{cm}^{2}$ (Fig. 4), under conditions suitable for most applications $\left(80 \%\right.$ and $50 \% \mathrm{H}_{2}$ and air utilization, respectively, at ambient pressures). The results are achieved by replacing the Pt cathode catalyst with a $\mathrm{Pt}_{0.2} \mathrm{Pd}_{0.8}$ alloy, where this particular composition was found most effective across the $\mathrm{Pt}_{\mathrm{x}} \mathrm{Pd}_{1-\mathrm{x}}$ system. Remarkably, at very low current densities $(<0.03 \mathrm{~mA} /$ $\mathrm{cm}^{2}$ ), the Pt and $\mathrm{Pt}_{0.2} \mathrm{Pd}_{0.8}$ alloy display similar overpotential and it is at higher current densities that the impact of the $\mathrm{Pd}$ is manifested. At this performance level, the SAFC stack costs would be about $\$ 500 / \mathrm{kW}$ (assuming PGM costs are $50 \%$ of total stack), and in order to be profitable at a system price of $\$ 1000 / \mathrm{kW}$, clearly additional development is necessary. It should be noted that despite the higher cathode performance using Pd-based catalysts, the challenge of durability remains. Furthermore, the reason for the enhanced activity is as yet unknown, although it may be relevant that analogous enhancements have also been observed for hydrogen electro-oxidation. ${ }^{20}$

Another strategy for enhancing power density is to increase the number density of catalyst sites (triple phase boundaries). As SAFC electrodes contain solid electrolyte particles, the most direct path to this goal is to decrease the electrolyte particle size and thereby increase the electrode-electrolyte contact area. This is a fundamental distinction from liquid or polymeric electrolyte systems, in which the catalyst surface area limits performance because the electrolyte can contact almost all catalyst particles. With this in mind Superprotonic spent considerable efforts to synthesize nano-sized solid acid particles and incorporate them into SAFC electrodes. These efforts were successful (Fig. 5), and indeed, the increase in catalysis for particles in the range of 100 to $200 \mathrm{~nm}$ agrees with the square root dependence of the effective charge transfer resistance on average particle size $\left(R_{c t}^{\text {eff }} \propto \sqrt{L}\right)$ determined for solid oxide fuel cell cathodes. ${ }^{21}$ However, this same dependence suggests that to lower the cathode overpotential to a target value of $300 \mathrm{mV}$ at $500 \mathrm{~mA} / \mathrm{cm}^{2}$, will require decreasing the solid acid particle size by another order of magnitude to $10 \mathrm{~nm}$, although the requirement may be relaxed if one simultaneously takes advantage of the high activity of Pt-Pd alloys. Nevertheless, in light of the plasticity of the electrolyte, small electrolyte particles (even 100 nm particles), or equivalently high surface-area structures, require support on or by another material that will maintain both the high surface area and interconnectivity of the electrolyte. Doing both simultaneously is challenging, but initial work at Caltech using an electrospray process shows promise. Here, all three phases in the electrode (catalyst, electrolyte, support material) are simultaneously deposited with nanoscale features (Fig. 6a).

In addition to decreasing the electrolyte particle size, the triple phase boundary in SAFC electrodes can be enhanced through judicious placement of the catalyst material. To this end, Superprotonic has developed a metalorganic chemical vapor deposition (MOCVD) process for deposition of $\mathrm{Pt}$ catalyst particles directly onto high surface area $\mathrm{CsH}_{2} \mathrm{PO}_{4}$ (Fig. 6b). The highly tunable process, in which the surface density of nanometric Pt particles can be easily adjusted, allows for nearly all the electrolyte surface to be active for catalysis, while providing nearly $100 \%$ Pt yield from the input precursor. Furthermore, there is strong evidence that the $\mathrm{Pt}$ particles act as inhibitors to electrolyte sintering. Accordingly, this process enables preparation of electrodes from only MOCVD coated electrolyte particles, and it is from such optimized structures that we have obtained the results shown in Figure 5.

These directions in SAFC research all center on cathode development for the reasons already highlighted: cost and durability. Continued progress along the present development path may ultimately enable SAFCs to attain platinum group metal (PGM) loadings of less than $1 \mathrm{mg} / \mathrm{cm}^{2}$ as is required for cost competitiveness against either other fuel cell or incumbent technologies. Even more tantalizing, however, is the prospect of eliminating 


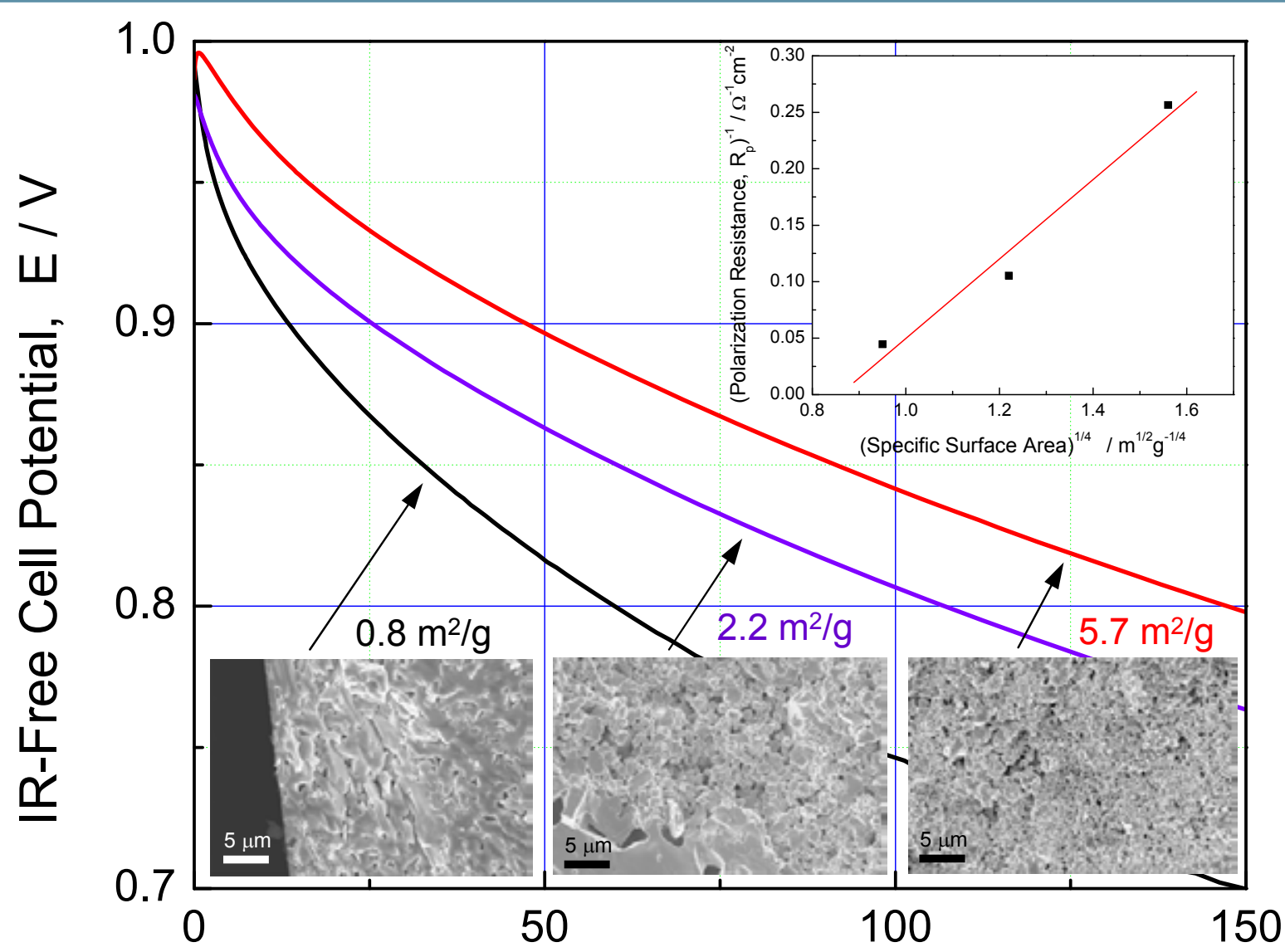

Current Density, $I / \mathrm{mA} \mathrm{cm}{ }^{-2}$

Fig. 5. Comparison of IR-free polarization curves of SAFCs incorporating different sized $\mathrm{CsH}_{2} \mathrm{PO}_{4}$ particles in the cathode. Scanning electron micrographs of the electrodes are shown and the inset presents the correlation between effective charge transfer resistance and average particle size, $L$ (of the electrolyte component of the cathode). IR correction was performed by subtracting out the ohmic resistance of the electrolyte.

PGMs entirely, a plausible scenario given the temperature of operation. Such an achievement, if attained without performance penalties, would render SAFCs extremely attractive from a raw materials cost basis, as the electrolytes themselves are extremely inexpensive.

In terms of systems development, no obviously insurmountable barriers have been identified, but some constraints have emerged from the experience gained at Superprotonic in prototyping the first SAFC power units. First, because the electrolyte is essentially protonically insulating below the superprotonic transition temperature, the system must heat the stack above the phase transition temperature $\left(\sim 230^{\circ} \mathrm{C}\right)$ before the stack is operable. At present, this is achieved using a heating sub-system similar to those employed in PAFCs systems. Second, the fact that the electrolyte is water soluble demands that the stack not fall below the dew point and condense liquid water within the MEAs. This is not particularly difficult to ensure given the stack inoperability below $\sim 230^{\circ} \mathrm{C}$; on either heat-up or cool-down, water generated in the stack at high temperatures is in the vapor form and hence can be easily purged. Third, due to the possibility $\mathrm{CsH}_{2} \mathrm{PO}_{4}$ dehydration at operational temperatures, both anode and cathode gas streams must be humidified to greater than $0.2 \mathrm{~atm}$ of water for safe operation of the stack. This is by far the most demanding systems level requirement for SAFCs as the energy required to heat the water

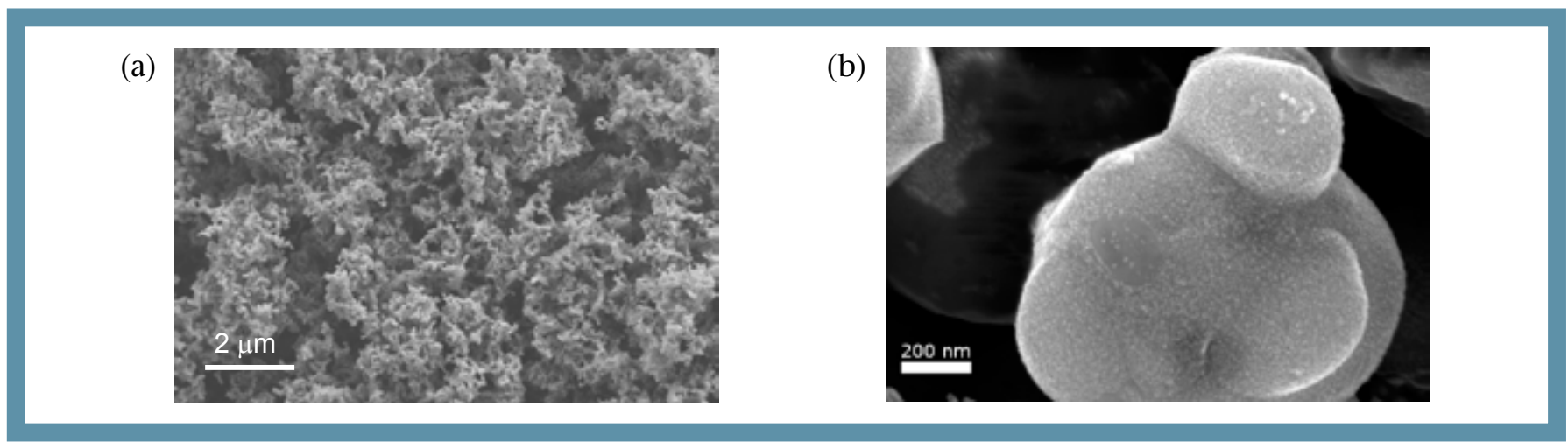

Fig. 6. Advanced electrode fabrication routes: (a) composite $\mathrm{CsH}_{2} \mathrm{PO}_{4}-\mathrm{Pt}$-carbon electrodes prepared by electrospray; and (b) ultrafine-Pt coating on porous, nanoscale $\mathrm{CsH}_{2} \mathrm{PO}_{4}$ obtained by metal-organic chemical vapor deposition (MOCVD). 
Chisholm, et al.

(continued from previous page)

for humidification must be recovered in order to achieve reasonable overall efficiencies. Moreover, for applications in which water neutrality is necessary (e.g., remote and portable power), water recovery from outgoing gas streams becomes an additional requirement and standard passive condensers may not be sufficient. While these constraints place engineering demands on SAFC power systems, the operation remains relatively simple, particularly in comparison to the complexity of PEMFC operation on reformed hydrogen.

\section{Conclusions}

Taken in total, the durability, power densities, precious metal loadings, and MEA active areas of state-of-the-art SAFCs render this nascent technology ready for immediate implementation in applications requiring hundreds of watts or less and for which high purity hydrogen may not be readily available. Typically, such applications are in small portable power for which methanol is often the fuel of choice and hence SAFCs are particularly attractive. To penetrate a broader range of markets, the remaining challenges in cost and durability, both of which are connected to cathode electrocatalysis rates, must be addressed. As outlined here, several opportunities for achieving competitive cost and performance targets appear viable. Success in this arena may enable the realization of the enormous environmental benefits that fuel cells continue to offer.

\section{About the Authors}

Dane A. Boysen is a co-founder of Superprotonic, Inc., in Pasadena, California, and served as the team lead for stack development. Dr. Boysen has investigated the transport properties, phase transitions, and atomic structure of solid acid proton conductors for more than 14 years. He carried out his doctoral studies in materials science at the California Institute of Technology, focusing on the phase behavior of a particular solid acid compound, $\mathrm{CsH}_{2} \mathrm{PO}_{4}$. Dr. Boysen went on to show that this compound is the most suited for real-world fuel cell applications of all the known solid acid compounds. After leading the highly successful stack development effort at Superprotonic, Dr. Boysen spent time studying nanoparticle synthesis at Iowa State University, and is now a Staff Scientist in Materials Science and Engineering at the Massachusetts Institute of Technology as part of a battery research team. He may be reached at dane.boysen@gmail. com.

Sukyal Cha is Director of Electrode Development at Superprotonic Inc.
Prior to joining Superprotonic, he was Director of Technology at PolyFuel Inc, Mountain View, California and Oorja Protonics Inc, Fremont, California; and a researcher at SRI International, Menlo Park, California and KIST, Seoul, Korea, for over 10 years. His research interests are micro and macro electrode structures, interface between ionic and electronic conducting materials, hydrogen generation, advanced electrochemical energy conversion systems, especially $\mathrm{H}_{2}$ /air fuel cells, direct methanol fuel cells, and supercapacitors. He may be reached at sukyal. cha@superprotonic.com.

Calum R.I. Chisholm is a co-founder and Vice-President of Superprotonic, Inc., an energy technology company established to develop and commercialize solid acid fuel cells. As a graduate student and then postdoctoral scholar in materials science at the California Institute of Technology, Dr. Chisholm investigated the fundamental properties of a class of materials known as superprotonic solid acids, named such for their ability to transform into highly conductive solidstate proton conductors under specific temperature/pressure conditions. In 2003, Dr. Chisholm co-founded Superprotonic with the goal of developing these scientifically fascinating materials into a commercially viable fuel cell technology for a wide range of power applications. Working with many exceptional collaborators, Dr. Chisholm has published 17 scientific papers in peer review journals and holds, or has applied for, eight patents. He may be reached at calum.chisholm@superprotonic.com.

Konstantinos P. Giapis is an associate professor of chemical engineering in the Division of Chemistry and Chemical Engineering at the California Institute of Technology. He received his $\mathrm{PhD}$ in chemical engineering from the University of Minnesota and continued as a postdoctoral member of the technical staff at AT\&T Bell Laboratories (Murray Hill, NJ) before joining Caltech. His research interests include ion-surface dynamics, plasma processing, and nanotechnology. He may be reached at giapis@caltech.edu.

Sossina M. HaIle is a professor of materials science and of chemical engineering at the California Institute of Technology. Before assuming her present position at Caltech in 1996, Haile was a member of the faculty at the University of Washington. Her research broadly encompasses solid state ionic materials and devices, with particular focus on fuel cells and thermochemical fuel production. In 2008 Haile was awarded an American Competitiveness and Innovation (ACI) Fellowship from the National Science Foundation in recognition of "her timely and transformative research in the energy field and her dedication to inclusive mentoring, education, and outreach across many levels." Since 2005 Haile has been a member of the National Materials Advisory Board, a committee serving the National Academies of Sciences and of Engineering. She may be reached at smhaile@caltech.edu.

Alexander B. Papandrew is a Senior Scientist at Superprotonic, Inc. Prior to his employment at Superprotonic, Dr. Papandrew received his PhD from the California Institute of Technology under the supervision of Brent Fultz. While at Caltech, he was a recipient of a National Defense Science and Engineering Grant fellowship. His research interests are in electrode development for solid acid fuel cells, artificial nanostructures, transition metal chemical vapor deposition, and X-ray and neutron scattering. He may be reached at alex. papandrew@superprotonic.com.

Kenji A. Sasaki is currently a graduate student in materials science at the California Institute of Technology. His research interests include heterogeneous catalysis and facile microstructural engineering for energy storage and conversion applications. Kenji's present focus is on electrocatalytic pathways in solid acid fuel cells, and his past studies include thermoelectric materials and electrochemical hydrogen pumps. He may be reached at kenji.sasaki@gmail. com.

Áron Varga received his BS and MS in materials science and engineering from the University of Cambridge, UK. He is currently a PhD candidate at the California Institute of Technology working under the supervision of Sossina M. Haile. His work focuses on fabricating composite nanostructured solid-acid fuel-cell electrodes. In addition to his experience as graduate research assistant, Aron has worked on modeling the oxygen reduction reaction at solid oxide fuel cell cathodes at MIT. He may be reached at avarga@caltech. edu.

Strahinja Zecevic is a Senior Electrochemist at Superprotonic, Inc. He received his $\mathrm{PhD}$ in electrochemistry from the University of Belgrade, Yugoslavia, in 1983. He has broad experience in both university (19761995) and corporate R\&D (1995-present) type research. He was a professor of electrochemical engineering and physical chemistry at the University of Belgrade; Senior Research Associate at Case Western Reserve University, Cleveland, $\mathrm{OH}$; Senior Scientist at Ceramatec Inc. and SARA Inc.; and Senior Fuel Cell Engineer at GE. His interest in electrochemistry involves electrode processes, particularly oxygen reduction electrochemistry, deposition, dissolution and corrosion of metals, batteries, fuel cells, sensors, low and high temperature systems based on 
use of ceramic membranes, and fluid delivery devices. He has 49 publications in scientific journals, ten patent disclosures, and four scholarly books. He may be reached at zeka.zecevic@ superprotonic.com.

\section{References}

1. S. M. Haile, D. A. Boysen, C. R. I. Chisholm, and R. B. Merle, Nature, 410, 910 (2001).

2. D. A. Boysen, T. Uda, C. R. I. Chisholm, and S. M. Haile, Science, 303, 68, (2004).

3. T. Norby, Nature, 410, 877 (2001).

4. S. M. Haile, C. R. I. Chisholm, K. Sasaki, D. A. Boysen, and T. Uda, Faraday Discussions, 134, 17 (2007).

5. A. I. Baranov, L. A. Shuvalov, and N. M. Shchagina, JETP Lett., 36, 459 (1982).

6. A. I. Baranov, V. P. Khiznichenko, V. A. Sandler, and L. A. Shuvalov, Ferroelectrics, 81, 1147 (1988).

7. A. Pawlowski, C. Pawlaczyk, and B. Hilzcer, Solid State Ionics, 44, 17 (1990).

8. M. Polomska, L. F. Kirpichnikova, T. Pawlowski, and B. Hilczer, Ferroelectrics, 290, 51 (2003).

9. C. R. I. Chisholm, PhD Thesis, California Institute of Technology, Pasadena, CA (2003).

10. C. R. I. Chisholm and S. M. Haile, Acta Crystallographica B, 55, 937 (1999).

11. R. B. Merle, C. R. I. Chisholm, D. A. Boysen, and S. M. Haile, Energy Fuels, 17, 210 (2003).

12. Y. Taninouchi, T. Uda, and Y. Awakura, Solid State Ionics, 178, 1648 (2008).

13. Y. K. Taninouchi, T. Uda, Y. Awakura, A. Ikeda, and S. M. Haile, J. Mater. Chem., 17, 3182 (2007).

14. J. $\mathrm{Wu}$, personal communication.

15. L. F. Kirpichnikova, A. A. Urusovskaya, and V. I. Mozgovoi, JETP Lett., 62, 638 (1995).

16. T. Uda and S. M. Haile, Electrochem. Solid-State Lett., 8, A245 (2005).

17. B. A. Peppley, J. C. Amphlett, L. M. Kearns, and R. F. Mann, Applied Catalysis A, 179, 21 (1999).

18. T. Uda, D. A. Boysen, C. R. I. Chisholm, and S. M. Haile, Electrochem. Solid-State Lett., $\mathbf{9}$, A261 (2006).

19. H. Stone, K. Mahadevan, K. Judd, H. Stein, V. Contini, J. Myers, J. Sanford, J. Amaya, J. Upton, and D. Paul, DOE Contract No. DEFC36-03GO13110; Economics of Stationary Proton Exchange Membrane Fuel Cells, Battelle (2006).

20. M. Louie, K. Sasaki, and S. M. Haile, ECS Trans., 13(28), 57 (2008)

21. C. W. Tanner, K. Z. Fung, and A. V. Virkar, J. Electrochem. Soc., 144, 21 (1997).

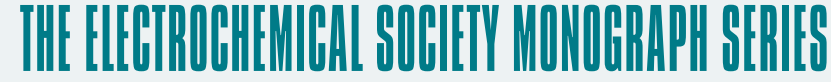

The following volumes are sponsored by ECS, and published by John Wiley \& Sons, Inc. They should be ordered from: ECS, 65 South Main St., Pennington, NJ 08534-2839, USA or www. electrochem.org/dl/bookstore.htm

\section{Just Published!}

\author{
Fuel Cells: Problems and Solutions \\ by $V$. Bagotsky \\ 320 pages. ISBN 978-0-470-23289-7
}

\section{Electrochemical Impedance Spectroscopy \\ by M. E. Orazem and B. Tribollet (2008) \\ 524 pages. ISBN 978-0-470-04140-6}

\section{Fundamentals of Electrochemical Deposition (2nd Edition)}

by M. Paunovic and M. Schlesinger (2006)

373 pages. ISBN 978-0-471-71221-3

\section{Fundamentals of Electrochemistry (2nd Edition) \\ Edited by V. S. Bagotsky (2005) \\ 722 pages. ISBN 978-0-471-70058-6}

Electrochemical Systems (3rd edition)

by John Newman and Karen E. Thomas-Alyea (2004)

647 pages. ISBN 978-0-471-47756-3

\section{Modern Electroplating (4th edition)}

Edited by M. Schlesinger and M. Paunovic (2000)

888 pages. ISBN 978-0-471-16824-9

\section{Atmospheric Corrosion}

by C. Leygraf and T. Graedel (2000)

3684 pages. ISBN 978-0-471-37219-6

Uhlig's Corrosion Handbook (2nd edition)

by $R$. Winston Revie (2000). paperback

1340 pages. ISBN 978-0-471-78494-4

\section{Semiconductor Wafer Bonding}

by Q. -Y. Tong and U. Gösele (1999)

297 pages. ISBN 978-0-471-57481-1

Corrosion of Stainless Steels (2nd edition)

by A. J. Sedriks (1996)

437 pages. ISBN 978-0-471-00792-0

Synthetic Diamond: Emerging CVD Science and Technology Edited by K. E. Spear and J. P. Dismukes (1994)

688 pages. ISBN 978-0-471-53589-8

\section{Electrochemical Oxygen Technology \\ by K. Kinoshita (1992) \\ 444 pages. ISBN 978-0-471-57043-1}

ECS Members will receive a discount. All prices subject to change without notice.

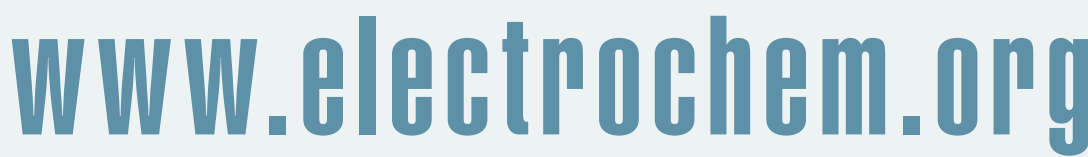

